\title{
Dermatitis Cruris Pustulosa et Atrophicans: Scarring Alopecia Beyond Scalp Hair
}

\author{
Ana Luísa João ${ }^{a}$ Nélia Cunha $^{a}$ Rita Ramos Pinheiro ${ }^{b}$ André Lencastre $^{b}$ \\ aDermatology Department, Centro Hospitalar Universitário de Lisboa Central, Lisbon, Portugal; ${ }^{\text {bDermatology }}$ \\ Department, Hospital da Luz, Lisbon, Portugal
}

\section{Keywords}

Dermatitis cruris pustulosa et atrophicans - Cicatricial alopecia · Folliculitis

\begin{abstract}
Dermatitis Cruris Pustulosa et Atrophicans (DCPA) was first described in 1952 in Nigeria and is nowadays regarded as a type of chronic folliculitis of tropical areas. It is often limited to the lower limbs of young adults, mostly in the second to third decades, with a unique clinical picture characterized by chronicity, relentless progression, therapy refractoriness, and permanent cicatricial changes. Trauma, occlusion, and microorganism selection contribute for its etiopathogenesis, which is deemed multifactorial but still incompletely understood. Despite its conspicuous clinical features, awareness of DCPA is apparently low, hence probably overlooked. We herein summarize the current state of knowledge regarding this distinct entity, and further present the first report in a patient from Bangladesh, and concurrently the first in Europe. Paucity of data, and unraveled definite etiology and treatment, highlight the need for further studies.
\end{abstract}

(c) 2022 S. Karger AG, Basel (c) 2022 S. Karger AG, Basel

www.karger.com/sad

\section{Introduction}

Dermatitis Cruris Pustulosa et Atrophicans (DCPA) was first described in 1952 by Clarke [1], who reported chronic symmetric pustules in the legs of dark-skinned individuals in west Nigeria. Subsequently, in the following decades, several cases have been recognized in tropical regions of Asia and Africa [1-5], and efforts to unravel the etiopathogenesis of this complex and difficultto-treat chronic entity have been made. This condition was later reviewed by Kaimal et al. [6]. Nevertheless, DCPA goes unmentioned in several clinical dermatology textbooks and in medical literature in general, and its awareness is apparently low, hence probably overlooked.

We herein describe a case that, to the best of our knowledge, is the first report of DCPA in a patient from Bangladesh, and concurrently the first in Europe. We aimed to summarize the current state of knowledge regarding DCPA and highlight the need for further studies.

\section{Historical Overview}

After being named by Clarke in 1952 in Nigeria [1], DCPA merited several names over the years, such as "Nigerian shin disease" [7]. In India, the disease has been

\footnotetext{
Karger"
}

Correspondence to:

Ana Luísa João, luisajoao92@gmail.com 
Table 1. Clinical grading of DCPA [1, 3, 4, 7-10, 12-28]

\begin{tabular}{|c|c|c|c|c|c|}
\hline Authors, year & Article type & Sex & Age, years & Country of origin & Aggravating factors/other associations \\
\hline Clarke [1] & Case report & Male & - & Nigeria & - \\
\hline Pardo-Castello [12] & Case series $(n=34)$ & Male & - & Cuba & Physical injury - sugarcane harvesters \\
\hline Miller [10] & Case report & Male & 46 & North America & Florist, painter, rubber industry, army \\
\hline Desai et al. [9] & Case series $(n=30)$ & Male:female $=27: 3$ & $15-35$ & India & Hypergammaglobulinemia \\
\hline Harman [7] & Case series $(n=15)$ & Male:female $=7: 8$ & $7-30$ & Nigeria & Vegetable oils (coconut oil) \\
\hline Sugathan et al. [13] & Case series $(n=79)$ & Male:female $=72: 7$ & 17-58 (mean 30.8) & India & $\begin{array}{l}\text { Alcohol, animal protein, sleeplessness, } \\
\text { excessive sweating; wet soil and cowdung }\end{array}$ \\
\hline Jacyk [14] & Case series $(n=30)$ & Male:female = 16:14 & $14-27$ & Nigeria & - \\
\hline Jacyk [15] & Case series $(n=81)$ & Male:female $=43: 38$ & $9-30$ & Nigeria & $\begin{array}{l}\text { Petroleum jelly, native oil (palm or kernel), } \\
\text { bacteriostatic soaps, pumice stone; rainy } \\
\text { versus dry season exacerbation }\end{array}$ \\
\hline Ting [3] & Case report $(n=3)$ & Male & $19-37$ & Malaysia & - \\
\hline Tiwari et al. [16] & Case series $(n=15)$ & Male & Mean 26 & India & $\begin{array}{l}\text { Vegetable oils (coconut and mustard), } \\
\text { workplace oils (cookers, drivers, mechanics) } \\
\text { Increased immunoglobulin G }\end{array}$ \\
\hline Parikh et al. [17] & Case series $(n=20)$ & Male & $21-30,50$ & India & $\begin{array}{l}\text { Vegetable oils (coconut and mustard); } \\
\text { allergic contact dermatitis to topic } \\
\text { antibiotics? }\end{array}$ \\
\hline Baslas et al. [18] & Case series $(n=570)$ & Male:female = 369:201 & $<10$ to $>50$ & India & - \\
\hline Shenoy et al. [19] & Original study $(n=45)$ & - & - & India & - \\
\hline Nanda [20] & Case report & Male & - & India & Epilation, sea water (fishermen) \\
\hline $\begin{array}{l}\text { Balachandran et al. } \\
\text { [21] }\end{array}$ & Case series $(n=25)$ & Male:female $=22: 3$ & - & India & Farmers, students \\
\hline $\begin{array}{l}\text { Kumarasinghe and } \\
\text { Kumarasinghe [22] }\end{array}$ & Case series $(n=51)$ & Male:female $=30: 21$ & 15-54 (mean 27.7) & Sri Lanka & $\begin{array}{l}\text { Cement (masons), saltwater and sea sand } \\
\text { (fishermen), mud/plants/fertilizer (farmers), } \\
\text { wood dust (saw-mill workers and } \\
\text { carpenters); coir fiber, stones or brushes }\end{array}$ \\
\hline Prasad [23] & Original study $(n=50)$ & Male & - & India & - \\
\hline Prasad et al. [8] & Original study $(n=50)$ & Male & - & India & Physical or chemical injury (farmers) \\
\hline $\begin{array}{l}\text { Kumar and } \\
\text { Muralldhar [24] }\end{array}$ & Case series $(n=3)$ & - & $20-30$ & India & Gardener, peon in office, manual laborer \\
\hline Das and Gogoi [25] & Original study $(n=80)$ & Female:male $=4.7: 1$ & $10-55$ & India & $\begin{array}{l}\text { Seasonal exacerbation (summer, winter, } \\
\text { none) }\end{array}$ \\
\hline Bens et al. [4] & Case report & Female & 17 & Burkina Faso & None \\
\hline Yahya [26] & Original study $(n=24)$ & - & - & Nigeria & - \\
\hline Kaimal et al. [27] & Case series $(n=37)$ & Male:female $=35: 2$ & 17-65 (mean 34.4) & India & $\begin{array}{l}\text { Sweat, terrycot/polyester full-length } \\
\text { trousers }\end{array}$ \\
\hline Kaimal et al. [28] & Case series $(n=37)$ & - & - & India & S. aureus carriage? \\
\hline
\end{tabular}


termed "chronic folliculitis of the legs" [8] or "therapyresistant pyogenic folliculitis of the legs" [9]. The disease was also described in 1 patient in North America, under the designation of "epilating folliculitis of the glabrous skin" and "lupoid sycosis of the legs" [10]. More recently, it has been mentioned as "chronic superficial folliculitis" [11]. These terms reflect the clinical features of the disease, which will be mentioned under the term "Dermatitis Cruris Pustulosa et Atrophicans" along the manuscript. Publications are summarized in Table 1.

\section{Epidemiology}

DCPA has been considered a disease of the tropics, for its higher incidence in these regions, namely in Asia and Africa. The reported prevalence varies between 0.4 and $4.8 \%[6,7,14,26], 3-4 \%$ in south India and $2.9 \%$ in Sri Lanka [22]. However, data should be regarded as an estimated mirror of incidence $[1-6,11]$ in the community, as only hospital-based data (outpatient clinics) are available. No definite cases of DCPA outside the tropical humid climates have been described after Miller's [10] original report in 1961 in North America, particularly in Europe (Table 1).

DCPA is nowadays regarded as a type of chronic folliculitis often limited to the lower limbs of young adults, mostly in the second to third decades. Sex predilection has varied from male to absent (Table 1) [1-6, 11]. Duration varies from a few months to 22 years, with most reports around $1-2$ years $[6,11]$.

\section{Clinical Presentation}

DCPA has peculiar clinical features that merit its categorization as a distinct clinical entity (summarized in Table 2). It is characterized by a protracted course of eruptions, which begin as follicular pustules and inflammation that progress to fibrotic lesions, atrophic plaques, and alopecia, mainly in the anterior portion of the legs, in a symmetric fashion (although unilateral onset is frequent). Involvement of forearms, face, and scalp has been rarely described. Despite possessing well-developed terminal hair, there are no reports of trunk or pubic region affection. The well-demarcated lesions can be distressingly itchy, without systemic symptoms, even in the presence of extensive lesions. Bleeding, pain, burning sensation, oozing, and scaling are less common symptoms. In addition, nutritional and hygiene status are usually adequate $[1-6,11]$.
Table 2. Clinical features of DCPA-Kaimal et al. [6]

Pustular folliculitis
Pruritus
Cutaneous pitting edema
Wry roughness in the involved area
Scale formation
Loss of skin marking
Remarkable shininess of the surface
Inevitable alopecia and atrophy of the affected skin
Complete absence of post-inflammatory hypo- or
hyperpigmentation
Symmetrical involvement of both legs between the knee and
ankle, mainly on the anterior surfaces of the shins

The borders of the eruption are usually well-defined, especially in the lower, sharper, margin. The dorsa of the feet and other areas of glabrous skin are never affected, as well as the ankle below the lower limit of the terminal hairs. Besides superficial and deep follicle-based pustules, there are various numbers of both follicle-based and nonfollicle-based papules [1-6, 11]. Scaling and eczematous changes have been frequently described. In long-standing disease, misdirected, horizontally orientated hair follicles give rise to haphazardous emerging of terminal hairs and subsequent sensation of wiry roughness. In addition, with chronicity, there is progression to alopecia, atrophy, and shininess of the involved skin. Finally, DCPA may undergo a "natural cure" once all the hairs in the affected area are irreversibly lost. Further, unlikely other inflammatory dermatosis, there is relative absence of post-inflammatory hyper- or hypopigmentation, notwithstanding being mentioned in some studies $[5-7,22]$.

According to the presumed state of the disease, Sugathan et al. [13] suggested a clinical grading for DCPA (Table 3). However, despite the distinctive clinical presentation and evolution, the individual manifestations and the extent to which they prevail vary from case to case, with possible overlap between grades. As such, Kaimal et al. [27] later proposed a revised classification (Table 3), with the primary criterion used being the predominance of pustules (grade I or II) or papules (grade III or IV), with other features such as alopecia, wiry roughness, and atrophy being further applied to classify those patients. As termed as a chronic condition, relapses are frequent, either in the form of relapses after past treatment or as a part of recurrence during the course of the disease per se $[1-6,11]$. 
Table 3. Clinical grading of DCPA

\begin{tabular}{lll}
\hline Grade & Sugathan et al. [13] & Kaimal et al. [27] \\
\hline I & $\begin{array}{l}\text { Follicular pustules only; some with well-defined perifollicular } \\
\text { erythema }\end{array}$ & $\begin{array}{l}\text { Almost complete alopecia with atrophic, shiny, and scaly } \\
\text { skin. Pustule no longer seen. Few discrete scaly papules at } \\
\text { the periphery }\end{array}$ \\
\hline II & $\begin{array}{l}\text { Predominantly follicular pustules with a significant number of } \\
\text { infiltrated papules around broken hairs. Papules show } \\
\text { excoriation marks, crusting, or a peripheral rim of white scales. } \\
\text { Alopecia is observable, but not marked. Wiry roughness caused } \\
\text { by broken or irregular hair }\end{array}$ & $\begin{array}{l}\text { Predominant lesions are follicular pustules, although } \\
\text { papules may also be seen in lesser numbers. Alopecia and } \\
\text { wiry roughness detected to some degree. Atrophy may be } \\
\text { present }\end{array}$ \\
$\begin{array}{ll}\text { Infiltrated scaly papules with a few scattered pustules in the } \\
\text { periphery. Atrophy, shininess, and marked alopecia }\end{array}$ & $\begin{array}{l}\text { Predominant lesions are papules, with a few scattered } \\
\text { pustules at the periphery. Alopecia and atrophy are } \\
\text { marked }\end{array}$ \\
\hline III & $\begin{array}{l}\text { Almost complete alopecia with atrophic, shiny, and scaly skin. } \\
\text { Pustule no longer seen. Few discrete scaly papules at the } \\
\text { periphery }\end{array}$ & $\begin{array}{l}\text { No pustules. Very few papules at the periphery. Complete } \\
\text { alopecia, with marked atrophy }\end{array}$ \\
\hline IV & \\
\hline
\end{tabular}

\section{Pathogenesis}

The etiopathogenesis is not completely understood, but deemed multifactorial, namely by repetitive trauma, climate, and occlusion (topical application of oils for cosmetic or medical purpose and/or clothing) (Table 1) [1-6, $11]$.

Physical or chemical injury is suggested by patient occupation. In an Indian study by Prasad et al. [8], most of the patients were farmers, while in Cuba more than a half of the patients were sugarcane harvesters who recognized the puncture of the stiff needles of the bark of the sugarcane [12]. The fact that the anterior aspects of the shins (which are the most affected location) are the most trauma-prone areas of the legs supports this hypothesis. On the other hand, fisherman are exposed to constant wetting of the skin, which seemed to be an important predisposing factor in one study in India [20]. Accordingly, season variations have been described, with summer and monsoon (humid and torrential rainfalls) exacerbations $[7,13,27]$. However, winter aggravation has also been mentioned $[11,16]$. Occupational exposure to other possible irritants beyond saltwater and sea sand has been pointed out by Kumarasinghe and Kumarasinghe [22], namely, cement, mud, plants, fertilizers, and wood dust. The authors suggested these agents to act synergically with minor trauma to facilitate the entry of pathogenic bacteria through the hair follicules [22]. Similarly, the use pumice stones scrubbers or conditions such as ichthyosis could be promoting factors [14, 22].

Dermatitis Cruris Pustulosa Atrophicans
Regarding clothing, in a study by Kaimal et al. [27], $61.35 \%$ of the patients mentioned worsening with synthetic clothe use (terrycot or polyester full-length trousers), while improving on wearing loose cotton clothing. This can be explained by the rationale that the less absorbent properties of the former propitiate occlusion and thus folliculitis. Notwithstanding, Tiwari et al. [16] reported no aggravation on wearing a soldier uniform.

Moreover, the occlusive quality of topical oils seems to be an important culprit, being frequently applied by the studied populations for cosmetic or medical purposes. These include vegetable oils (especially coconut oil). Occlusion leads to increased hydration of the stratum corneum, rendering it more prone to trauma once moist skin has a higher friction coefficient [15]. Scaly DCPA lesions lead patients to continue applying oil to the affected areas, perpetuating the occlusive component of the disease. However, later studies argued that lesions were localized to the lower limbs despite oil being applied to the whole body, and patch tests were negative [17].

In regard to the latter predisposing factor, South American dermatological literature interestingly mentions the term "elaioconiosis" $[29,30]$ (an apparent misnomer as it combines the Greek words for oil and dust, élaion and konis). This is a condition all in all similar and probably synonymous with oil acne (a type of occupational acne) that arises due to mechanical follicular obstruction (such as in acne cosmetica or pommade acne) by heavy ongoing percutaneous exposure to cutting oils and greases. Even though oil acne is an important differential, it has not been reported to cause cicatricial alopecia as seen in DCPA and 
has an apparent preference for occupationally exposed areas (such as the upper body and limbs) [31,32].

Another factor contributing to DCPA is possible microorganism selection through the use of bacteriostatic soaps $[1-6,11]$. The latter may be responsible for the almost invariable isolation of Staphylococcus spp in pus from the lesions, mostly coagulase-positive $S$. aureus, making it virtually the prime etiological agent [27]. Nevertheless, its true pathogenicity is still a matter of debate, including the carrier state. Kaimal et al. [28] aimed to address the contribution of $S$. aureus nasal carriage by phage typing between the isolated organisms of pustules and carrier sites, which were identical in 5 out of 21 carriers, making it difficult to establish its true pathogenicity. Additional organisms that have grown in culture from DCPA pustules include Pseudomonas spp., Klebsiella spp., and beta-hemolytic Streptococcus, but no causality can be inferred. Trichophyton rubrum has also been considered as involved agent, although no evidence was found [6].

Finally, immunological abnormalities have also been proposed, based on the chronicity of the dermatosis that would favor the contribution of an immunological mechanism. In this regard, hypergammaglobulinemia has been implicated [9], but further deemed unrelated [13]. Tiwari et al. [16] showed increase of immunoglobulin G levels in all 15 soldiers. Parikh et al. [17] findings suggested that there was no abnormality of polymorphonuclear function. In sum, DCPA immunology remains to be elucidated, requiring further studies.

\section{Histopathology}

DCPA histology was revised by Kaimal et al. [6]. The epidermis shows moderate hyperkeratosis and parakeratosis in loose bands of stratum corneum. In early lesions, there is nonspecific focal round cell infiltration of the dermis and focal infiltration of the mouth of the hair follicle by polymorphs. There are intraepidermal and subcorneal pustules containing leukocytes, with surrounding infiltration by neutrophils, lymphocytes, and occasional eosinophils. Well-developed pustular lesions showed a "wine glass"-shaped abscess (involving the upper part of the hair follicle, sparing the bulb, or root of the hair). Furthermore, lymphocytic and plasma cell infiltration of the sweat glands and hair follicles can also be seen [6].

In the cicatricial stage, there is atrophy of the rete ridges and appendages, with upper dermal fibrosis and focal collection of round cells around the appendages. In this stage, several additional epidermal and dermal changes
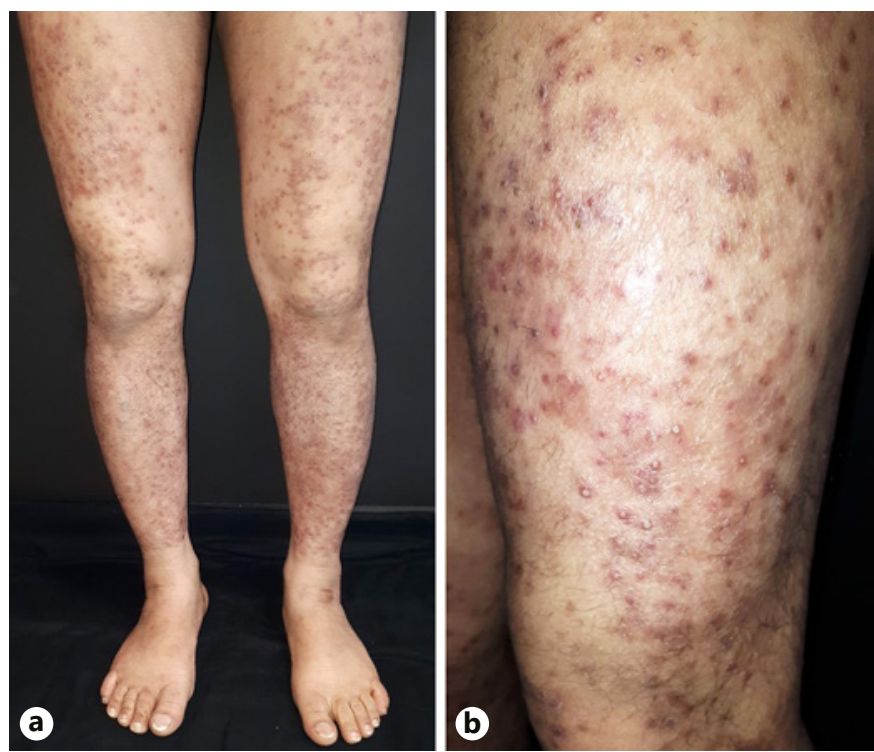

Fig. 1. a Multiple pustules and lichenified papules and plaques on the lower limbs with scarring alopecia. b Greater amplification.

have been described, including hyperkeratosis, parakeratosis, acanthosis, spongiosis, and occasional red blood cell-containing vesicles [6].

\section{Treatment}

Treatment is commonly unsatisfactory, and thus DCPA can be considered "therapy-resistant." Therapeutic options were revised by Kaimal et al. [6], with variable success rates reported for antiseptics, topical mupirocin, systemic antibiotics (cotrimoxazole, tetracyclines, rifampicin, and ciprofloxacin), pentoxifylline, dapsone, and psoralen plus ultraviolet-A $[1-6,11]$. On the other hand, DCPA seems to undergo a "natural cure" once the hairs in the affected areas are permanently lost [6]. We therefore advocate the avoidance of risk factors and combination therapy with antiseptic lotions and long-term systemic antibiotics, which should be initiated as early as possible, since its refractoriness and relentless progression to alopecia and atrophy of the affected site.

\section{Author's Experience}

A 34-year-old man from Bangladesh presented with a 2-year history intermittent flares of pruritic lesions on the legs. He also reported the regular application of oily prep- 
Fig. 2. a "Early lesion" - superficial folliculitis changes with a well-developed "wine glass"-shaped abscess on the follicular ostium with a hair shaft within. An accompanying neutrophilic infiltrate on the dermis can also be seen (HE. $\times 100)$. b "Later lesion" - a mixed infiltrate composed of lymphocytes and neutrophils, histocytes, and giant cells is seen above the lower hair follicle segments (HE. $\times 100)$.
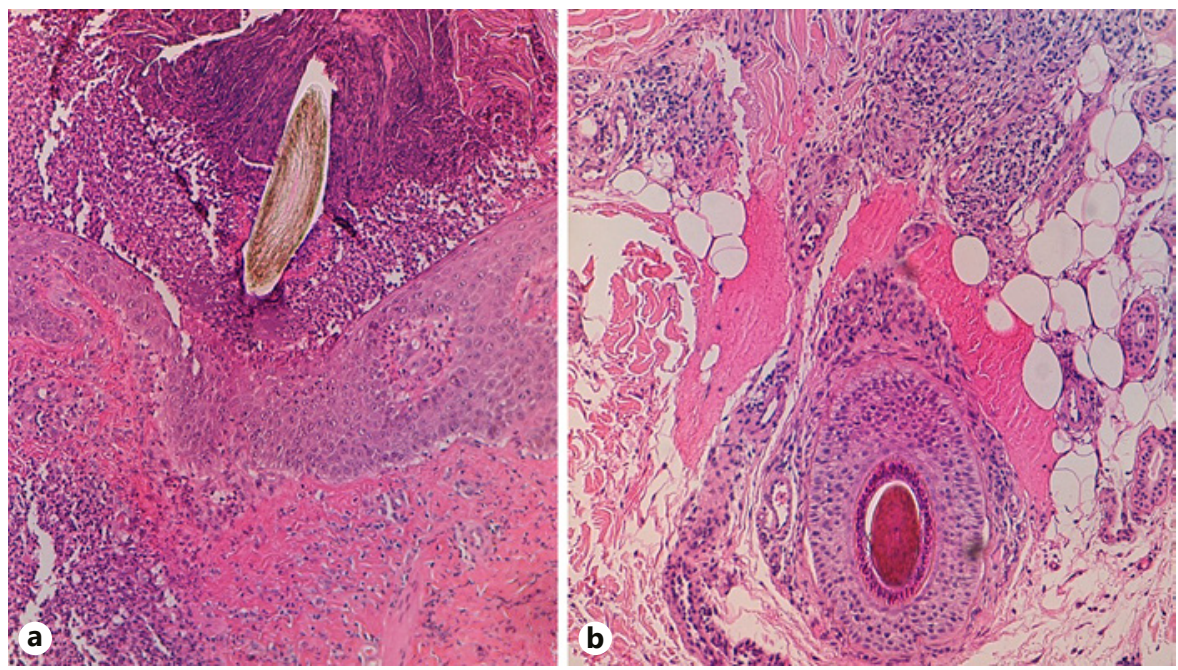

arations (petroleum jelly and olive oil) due to excessive dryness. On clinical examination, there were multiple follicular pustules and lichenified papules and plaques on the anterior aspects of the thighs and shins, with areas of cicatricial alopecia, marked post-inflammatory hyperpigmentation and scant excoriations (Fig. 1). Two skin biopsies, obtained in different timepoints revealed perifollicular parakeratotic hyperkeratosis with follicular destruction and a perifollicular neutrophilic infiltrate with giant cells. Histological examination was compatible with folliculitis (Fig. 2). Methicillin-sensitive staphylococcus aureus was isolated in culture of pus from a pustule, with a negative mycological exam ( $\mathrm{KOH}$ and culture). The patient was instructed to stop using oily skin preparations, and, for a 5-year follow-up period, he did several cycles of tetracyclines (doxycycline), clindamycin, and oral antifungals (terbinafine and itraconazole), with insignificant improvement. He was also tried on bleach baths, topical mupirocin (treatment and decolonization regimens), and potent topical corticosteroids, with little response. Isotretinoin $(0.1 \mathrm{mg} / \mathrm{kg} /$ day $)$ was then started, resulting in a substantial reduction of the number of new episodes.

The conspicuous clinical features of DCPA allowed its differentiation from common pyogenic infections of the skin, including banal staphylococcal folliculitis and fungal folliculitis (ruled out by negative mycological studies) [27]. In addition, there are other disorders of the hair follicle that can result in scarring alopecia, such as folliculitis decalvans, sycosis barbae, folliculitis keloidalis, and hidradenitis suppurativa to name a few. Their pathogenesis is complex and/or uncertain, with bacterial infection playing a protean role [33]. Folliculitis decalvans-like lesions on the limbs with sparing of the scalp, has been an- ecdotally described [34]. We concur with the points made by Thakur et al. [35], in response to the aforementioned, and therefore favor the term DPCA, for this primary scarring alopecia better known to our South Asian colleagues. All unidentified parallels between DCPA and other scarring neutrophilic alopecias need then to be clarified, in the future. In our case, the observed improvement with isotretinoin might only represent a slow transition toward a "burned out" phase of cicatricial alopecia.

\section{Conclusion}

Although a seemingly common entity, DCPA has received little attention in dermatological literature and we might even question its existence since it may be undistinguishable from other folliculitides. The present case is, to the best of our knowledge, the first report of DCPA in a patient from Bangladesh, and concurrently the first in Europe. Paucity of data, combined with a unique clinical picture characterized by chronicity, relentless progression, therapy refractoriness, and permanent cicatricial changes, highlight the need for further studies on DCPA.

\section{Statement of Ethics}

The authors have no ethical conflicts to disclose. The research was conducted ethically in accordance with the World Medical Association Declaration of Helsinki. Institutional Ethics Committee guidelines were applied and approval was waived. The Ethics Committee number is CHULC-CI $n^{\circ} 033 / 2020$. Written informed consent was obtained from the patient for publication of this case report and any accompanying images. 


\section{Conflict of Interest Statement}

The authors have no conflicts of interest to declare.

\section{Funding Sources}

The authors have received no external funding.

\section{Author Contributions}

Dr. Ana Luísa João: contributed to data analysis and interpretation, and drafting of the manuscript. Dr. Nélia Cunha: contributed to interpretation of data and revision of the article. Dr. Rita Ramos Pinheiro: contributed to interpretation of data and revision of the article. Dr. André Lencastre: contributed to data collection, data analysis and interpretation, and revision of the article.

\section{References}

1 Clarke GH. A note on dermatitis cruris pustulosa et atrophicans. Trans R Soc Trop Med Hyg. 1952;46(5):558-9.

2 Jacyk WK. Clinical and pathologic observations in dermatitis Cruris Pustulosa Et Atrophicans. Int J Dermatol. 1978;17(10):802-7.

3 Ting HC. Dermatitis cruris pustulosa et atrophicans: case reports. Med J Malaysia. 1984; 39(1):82-4.

4 Bens G, Franck F, Diatto G, Preney L, Darie H, Géniaux M. Dermatitis cruris pustulosa et atrophicans: a frequent but poorly understood tropical skin condition-a case report from Burkina Faso. Int J Dermatol. 2008; 47(5):473-5.

5 Razera F, Olm GS, Bonamigo RR. Neutrophilic dermatoses: part II. An Bras Dermatol. 2011;86(2):195-209.

6 Kaimal S, D’Souza M, Kumari R. Dermatitis cruris pustulosa et atrophicans. Indian J Dermatol Venereol Leprol. 2009;75(4):348-55.

7 Harman RRM. Dermatitis Cruris Pustulosa Et Atrophicans, the Nigerian Shin disease. $\mathrm{Br}$ J Dermatol. 1968;80(2):97-107.

8 Prasad P, Anandhi V, Jaya M. Chronic folliculitis: a clinico-epidemiological study. Indian J Dermatol Venereol Leprol. 1997;63:304-6.

9 Desai SC, Shah BH, Modi PJ, Sethi NC. Therapy resistant pyogenic folliculitis on legs in the adult males with hypergammaglobulinemia. Indian J Dermatol Venereol. 1964; 30:89-97.

10 Miller RF. Epilating folliculitis of the glabrous skin. Report of a case, histopathologic and nosologic study. Arch Dermatol. 1961;83:77784.

11 Saranya TM, Sasidharanpillai S, Ajithkumar $\mathrm{K}$. Descriptive study on the clinical profile and demography of patients with chronic folliculitis of leg attending a tertiary referral center. J Skin Sex Transm Dis. 2020 Oct 15;2: 104-9.

12 Pardo-Castello V. Dermatology in a tropical rural zone; reference to occupational dermatoses. AMA Arch Derm. 1956;74:115-27.
13 Sugathan P, Zacariah J, Joy M. Folliculitis cruris pustulosa et atrophicans. Indian J Dermatol Venereol Leprol. 1973;39:35-40.

14 Jacyk WK. Septrin in the treatment of dermatitis cruris pustulosa et atrophicans. Br J Dermatol. 1976;95:71-3.

15 Jacyk WK. Clinical and pathologic observations in dermatitis cruris pustulosa et atrophicans. Int J Dermatol. 1978;17:802-7.

16 Tiwari VD, Ramji C, Tutakne MA, Singh G, Dutta RK. Dermatitis cruris pustulosa et atrophicans. Indian J Dermatol Venereol Leprol. 1987 Mar-Apr;53(2):116-7.

17 Parikh DA, Thatte UM, Fernandez RJ, Shroff PS, Wagle UD, Iyer EE. Clinical, bacteriological and immunological profile of 20 patients with dermatitis cruris pustulosa et atrophicans. Indian J Dermatol Venereol Leprol. 1989;55:237-40.

18 Baslas RG, Arora SK, Mukhija RD, Mohan L, Singh UK. Organisms causing pyoderma and their susceptibility patterns. Indian J Dermatol Venereol Leprol. 1990;56:127-9.

19 Shenoy K, Srinivas C, Sharma S, Shivananda P, Shetty J. Efficacy of clotrimoxazole and PUVA for the management of chronic folliculitis of legs. Indian J Dermatol Venereol Leprol. 1990;56:223-5.

20 Nanda G. Epilating folliculitis: a possible predisposing factor. Indian J Dermatol Venereol Leprol. 1991;57:203.

21 Balachandran C, Malpani S, Srinivas CR. Ciprofloxacin therapy in chronic folliculitis of legs. Indian J Dermatol Venereol Leprol. 1995;61:212-3.

22 Kumarasinghe SP, Kumarasinghe MP. Chronic folliculitis in Sri Lanka. Indian J Dermatol Venereol Leprol. 1996;62:79-82.

23 Prasad PV. Rifampicin and dapsone in superficial pustular folliculitis. Indian J Dermatol Venereol Leprol. 1996;62:16-8.
24 Kumar B, Muralidhar S. Mupirocin in folliculitis cruris pustulosa et atrophicans. Indian J Dermatol Venereol Leprol. 1998;64(4):207.

25 Das J, Gogoi J. The efficacy of PUVA therapy in dermatitis cruris pustulosa et atrophicans. Ind J Dermatol. 1999;44(4):179-82.

26 Yahya H. Change in pattern of skin disease in Kaduna, north-central Nigeria. Int J Dermatol. 2007;46(9):936-43.

27 Kaimal S, D'Souza M, Kumari R, Parija SC, Sistla S, Badhe BA. Dermatitis cruris pustulosa et atrophicans revisited: our experience with 37 patients in south India. Int J Dermatol. 2009;48(10):1082-90.

28 Kaimal S, D'Souza M, Sistla S, Parija SC. Phage typing in dermatitis cruris pustulosa et atrophicans: does staphylococcal carrier status have a role? Int J Dermatol. 2012;51(11): 1335-9.

29 Valgas N, Salaro CP, Bornhausen-Demarch E, Bonora CJ, Broce AA. Elaioconiosis: case report. An Bras Dermatol. 2011;86(4 Suppl 1): S53-6.

30 Olivi WR. Follicular elaioconioses (oil-acne). Rev Bras Med. 1971;28(3):119-20.

31 Abou-ElWafa HS, Albadry AA, El-Gilany AH, Ismael AF. Dermatoses among automobile mechanics in Mansoura, Egypt. Arch Environ Occup Health. 2018;73(11):42-77.

32 Mark Wilkinson S. Chapter 16: occupational dermatosis. In: Bolognia J, Schaffer JV, Cerroni L, editors. Dermatology; 2018.

33 Burns T, Breathnach S, Cox N, Griffiths C. Rook's textbook of dermatology. 7th ed. Oxford: Blackwell Science; 2004. Vol. 27.p. 1-85.

34 Yang A, Hannaford R, Kossard S. Folliculitis decalvans-like pustular plaques on the limbs sparing the scalp. Australas J Dermatol. 2020; 61(1):54-6.

35 Thakur V, Bishnoi A, Kumar S, Vinay K, Aggarwal D, Dass Radotra B. Response to "folliculitis decalvans-like pustular plaques on the limbs sparing the scalp". Australas J Dermatol. 2020 May;61(2):e252-4. 